\title{
Aspectos Moleculares da Solvatação do ĺon Fluoreto em Água e DMSO
}

\author{
Natália M. Silva \& Josefredo R. Pliego Jr.
}

\section{Introdução}

O efeito do solvente é essencial na descrição de reações em solução, principalmente reações iônicas. No caso de reações do tipo ion-molécula, é necessário a solubilização de ambos o substrato orgânico e o íon inorgânico. Solventes como água e metanol usualmente tem uma forte solvatação de ânions, tornando sua reatividade muito baixa. A introdução dos solventes apróticos dipolares há mais de 50 anos atrás permitiu a solubilização de sais inorgânicos e dos compostos orgânicos simultaneamente. Ao mesmo tempo, a menor solvatação dos ânions nestes solventes levou a uma maior reatividade destes. ${ }^{1}$

Apesar da importância deste efeito bem conhecido dos solventes apróticos dipolares, com sua larga aplicação em química orgânica sintética, e da publicação de escalas de solvatação, ${ }^{2,3}$ os aspectos moleculares da diferença de solvatação de ânions pequenos como o fluoreto em água e DMSO não foi investigada ainda. Neste trabalho foram feitos cálculos de energia em nível MP2 utilizando moléculas de água como solvente prótico e moléculas de dimetilsulfóxido (DMSO) como solvente aprótico dipolar para solvatar o íon fluoreto. Nosso objetivo foi entender a primeira camada de solvatação, que é essencial para descrever reatividade química em solução. ${ }^{4}$

\section{Metodologia}

Os complexos formados pelo ín fluoreto e moléculas de água ou DMSO foram investigados em nível ab initio. As geometrias foram otimizadas utilizando o método
MP2 com bases aug-cc-pVDZ. Após otimização de geometria, foram feitos cálculos da energia no ponto, também em nível MP2, mas utilizando uma base mais estendida, aug-cc-pVTZ.

\section{Resultados e Discussões}

A energia de interação do íon fluoreto com uma molécula de água é de $-31,88 \mathrm{kcal} / \mathrm{mol}$. Com adição de mais moléculas de água, a energia de formação do cluster vai se tornando mais negativa, apesar de que a cada nova molécula adicionada, a energia diminui menos, o que já era esperado. Com 4 moléculas de água, o cluster é estável por $-85,05 \mathrm{kcal} / \mathrm{mol}$. As estruturas estão mostradas na Figura 1. Como podemos observar, metade do íon fluoreto fica completamente solvatado por 4 moléculas de água.

Tabela 1: Dados de energia para formação dos clusters do íon Fluoreto com solvente prótico $\mathrm{H} 2 \mathrm{O}$, e aprótico DMSO, em nível de cálculo MP2/aug-cc-pVTZ//MP2/aug-cc-pVDZ.*

\begin{tabular}{|c|c|}
\hline & $\square \mathrm{E}$ \\
\hline $\mathrm{F}^{-}\left(\mathrm{H}_{2} \mathrm{O}\right)$ & $-31,88$ \\
\hline $\mathrm{F}^{-}\left(\mathrm{H}_{2} \mathrm{O}\right)_{2}$ & $-52,34$ \\
\hline $\mathrm{F}^{-}\left(\mathrm{H}_{2} \mathrm{O}\right)_{3}$ & $-69,27$ \\
\hline $\mathrm{F}^{-}\left(\mathrm{H}_{2} \mathrm{O}\right)_{4}$ & $-85,05$ \\
\hline $\mathrm{F}^{-}\left(\mathrm{CH}_{3} \mathrm{SOCH}_{3}\right)$ & $-32,79$ \\
\hline $\mathrm{F}^{-}\left(\mathrm{CH}_{3} \mathrm{SOCH}_{3}\right)_{2}$ & $-55,72$ \\
\hline
\end{tabular}

*Valores em $\mathrm{kcal} / \mathrm{mol}$ 


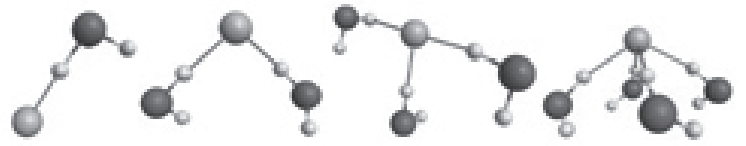

F- $\mathrm{H}_{2} \mathrm{O}$ F- $\left(\mathrm{H}_{2} \mathrm{O}\right)_{2} \mathrm{~F}-\left(\mathrm{H}_{2} \mathrm{O}\right)_{3} \mathrm{~F}-\left(\mathrm{H}_{2} \mathrm{O}\right)_{4}$

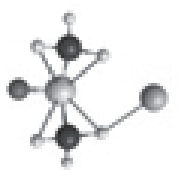

\section{F- $\mathrm{CH}_{3} \mathrm{SOCH}_{3} \quad \mathrm{~F}-\left(\mathrm{CH}_{3} \mathrm{SOCH}_{3}\right)_{2}$}

Figura 1: Complexos do íon fluoreto com água e DMSO.

Para complementar a argumentação de que o tamanho das moléculas do solvente tem um papel importante na energia livre de solvatação, observamos que cada um dos clusters com 2 DMSO e 4 águas terão ainda de ser solvatados pelo restante do solvente. Considerando o modelo de Born, cuja energia livre de solvatação por um dielétrico é dada por:

$$
\Delta G_{\text {solv }}=-\frac{1}{2} \frac{1}{4 \pi \varepsilon_{o}} \frac{q^{2}}{R}\left(1-\frac{1}{\varepsilon}\right)
$$

notamos que a energia livre de solvatação é inversamente proporcional ao tamanho do íon (R, raio do ín). Ou seja, o cluster de fluoreto com 4 moléculas de água deveria ser melhor solvatado do que com 2 moléculas de DMSO.

Tabela 2: Dados da Análise da Decomposição de Energia (EDA) para os complexos, em nível de cálculo MP2, todos calculados com conjunto de função de base aug-cc-pVTZ.*

\begin{tabular}{|c|c|c|c|c|}
\hline & Eletrostática & $\begin{array}{c}\text { Troca- } \\
\text { Repulsão }\end{array}$ & Polarização & Dispersão \\
\hline$\left(\mathrm{H}_{2} \mathrm{O}\right) \mathrm{F}^{-}$ & $-44,02$ & 40,91 & $-26,99$ & $-1,78$ \\
\hline$\left(\mathrm{H}_{2} \mathrm{O}\right)_{2} \mathrm{~F}^{-}$ & $-72,46$ & 57,41 & $-33,39$ & $-3,90$ \\
\hline$\left(\mathrm{H}_{2} \mathrm{O}\right)_{3} \mathrm{~F}^{-}$ & $-96,05$ & 67,63 & $-35,07$ & $-5,78$ \\
\hline$\left(\mathrm{H}_{2} \mathrm{O}\right)_{4} \mathrm{~F}^{-}$ & $-117,32$ & 74,9 & $-32,53$ & $-10,10$ \\
\hline $\mathrm{F}^{-}\left(\mathrm{CH}_{3} \mathrm{SOCH}_{3}\right)$ & $-40,51$ & 33,97 & $-22,92$ & $-3,33$ \\
\hline $\mathrm{F}^{-}\left(\mathrm{CH}_{3} \mathrm{SOCH}_{3}\right)_{2}$ & $-67,11$ & 48,25 & $-31,04$ & $-5,82$ \\
\hline
\end{tabular}

Com o intuito de compreender melhor a natureza das interações moleculares nestes complexos, fizemos também cálculos EDA (Energy Decomposition Analysis). ${ }^{5}$ A energia eletrostática para o cluster do fluoreto com moléculas de água torna-se cada vez mais negativa ao se adicionar mais moléculas de água, ao passo que sua energia de troca-repulsão tornase cada vez mais positiva. Entretanto, enquanto a energia eletrostática aumenta por um fator de 2,7, a contribuição de troca-repulsão aumenta por um fator de apenas 1,8 . Isto pode ser explicado pelo aumento da distância entre o fluoreto e os hidrogênios, que inicia em $1.414 \AA$ com uma água até $1.713 \AA$ com quatro águas, aliviando assim o termo de troca-repulsão, de curto alcance.

No caso do termo de polarização, que chega a ser $61 \%$ da interação eletrostática com uma molécula de água, é evidente a forte polarização da água pelo pequeno íon fluoreto. Este termo apresenta uma variação pequena com o aumento das águas, indo de $-27,0 \mathrm{kcal} / \mathrm{mol}$ com uma água e atingindo um valor mais negativo com três moléculas de água, $-35,07$ $\mathrm{kcal} / \mathrm{mol}$. Esta contribuição se torna $-32,53 \mathrm{kcal} / \mathrm{mol}$ com quatro águas. Este mínimo pode ser explicado pelo arranjo das moléculas de água, onde a simetria de quatro águas em torno do fluoreto inibe a polarização maior em uma direção. Além disso, o aumento da distância das moléculas de água ao fluoreto gera um campo elétrico menor nas águas, e portanto, menor polarização. A energia de dispersão segue a tendência esperada de aumentar (mais negativa) com a quantidade de elétrons no sistema.

Nos clusters do fluoreto com moléculas de DMSO, a tendência nas energias é bem mais previsível. Comparando com o cluster de água, vemos que as energias eletrostática e de polarização são de menor magnitude com DMSO, mas os termos de trocarepulsão também. Isto ocorre pelo fato do DMSO ficar bem mais distante do fluoreto do que a água. Por exemplo, no complexo do fluoreto com apenas uma molécula de DMSO a distância hidrogênio-fluoreto é de 1.821 Å e com duas moléculas de DMSO é de 1.929 Å. Como consequência, o termo de troca-repulsão é menor, e os termos eletrostáticos e de polarização são menos negativos. 


\section{Conclusão}

A interação do íon fluoreto com uma ou duas moléculas de DMSO é mais negativa do que sua interação com uma ou duas moléculas de água, desafiando a visão de que ânions interagem fracamente com DMSO. Entretanto, o fato de a molécula de DMSO ser bem maior do que a molécula de água leva a uma interação mais forte do F- com a primeira camada de solvatação de água do que com a primeira camada de solvatação de DMSO. Como consequência, o fluoreto é muito mais solvatado em meio aquoso do que em DMSO, levando a sua maior reatividade em DMSO.

\section{Agradecimentos}

Os autores agradecem ao CNPq e a FAPEMIG.

\section{Referências}

1. A.J. Parker, Chem. Rev. 69 (1969) 1.

2. J.R. Pliego, E.L.M. Miguel, J. Phys. Chem. B 117 (2013) 5129.

3. .R. Pliego Jr, J.M. Riveros, Phys. Chem. Chem. Phys. 4 (2002) 1622.

4. .R. Pliego Jr, J. Phys. Chem. B 113 (2009) 505.

5. P. Su, H. Li, J. Chem. Phys. 131 (2009) 014102.

\section{Natália M. Silva* \& Josefredo R. Pliego Jr.}

Departamento de Ciências Naturais, Universidade Federal de São João del-Rei

*E-mail: natalia.more.silva@gmail.com 